\title{
Catalytic Oxidation of Styrene in the Presence of Square Planar Cobalt(III) Complexes of Polyanionic Chelating Ligands
}

\author{
Terrence J. Collins,* Shigeko Ozaki, and Thomas G. Richmond \\ The Chemical Laboratories, California Institute of Technology, Pasadena, CA 91125, U.S.A.†
}

Styrene has been catalytically oxidised in the presence of iodosoarenes and square planar cobalt(III) complexes of polyanionic chelating (PAC) ligands; possible intermediates in these oxygen atom transfer reactions include cobalt(v)-oxo complexes.

The benefits that might accompany the development of new homogeneous catalysts for selective oxidation reactions are alluring. One promising approach is to produce novel metaloxo complexes, often as reactive intermediates, and study their usefulness in atom transfer oxidations. ${ }^{1,2}$ At the present time, the class of all transition metal-terminal oxo complexes has distinct boundaries which include the following. (i) All well-characterized terminal oxo complexes of transition metals have a d-electron count less than or equal to four. (ii) Stable terminal metal-oxo species are not found to the right of iron in the periodic table. The first condition apparently reflects a binding requirement that sufficient vacant $d-\pi$ orbital space be available on the metal centre to allow for the formtion of at least one $\pi$ bond. In cases where the d-electron count is greater than four, oxo ligands are found in bridging environments. The second limitation is possibly a manifestation of the first; to the right of iron in the periodic table the oxidation states with four or fewer d-electrons are less accessible. We have been interested in expanding the range of terminal oxo complexes to include examples with transition elements to the right of iron in the periodic table. Indirect evidence for the possible existence of such species is presented in this report. The approach has been to develop oxidation resistant polyanionic chelating (PAC) ligands that have large donor capacities such that unusual high oxidation state complexes of later metals can be produced. ${ }^{3}$ The synthesis of

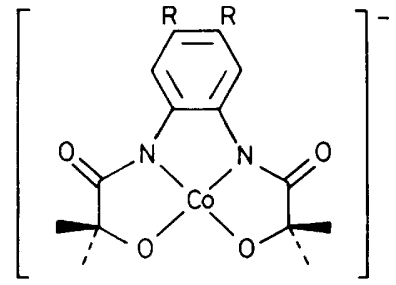

(1) $; \mathrm{R}=\mathrm{H}$

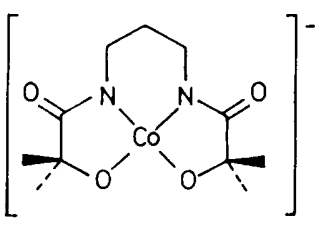

(4)

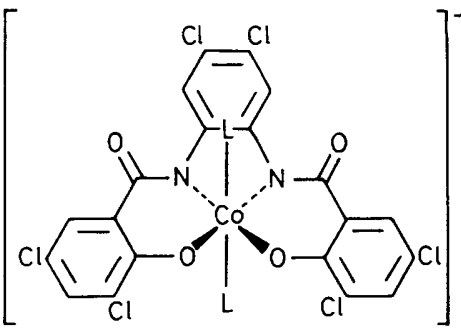

(5): $\mathrm{L}=\mathrm{H}_{2} \mathrm{O}$
(2); $\mathrm{R}=\mathrm{Cl}$

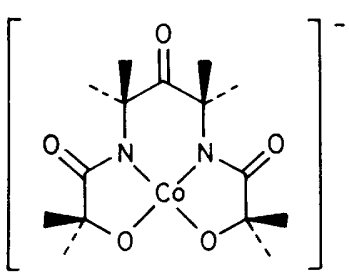

(3) stable square planar cobalt(III) complexes having remarkably small axial Lewis acidities has recently been reported. ${ }^{4}$ It is shown here that alkene epoxidation by iodosylarenes proceeds readily in the presence of these species.

A number of salts of anionic square planar cobalt(III)-PAC complexes were employed (1)-(5). Styrene oxidation was performed in acetonitrile $(20 \mathrm{ml})$ at $0{ }^{\circ} \mathrm{C}$ under nitrogen gas with mechanical stirring using $\mathrm{Na}\left[\mathrm{Co}\left(\eta^{4}-\mathrm{PAC}\right)\right]$, or $\left[\mathrm{PPh}_{4}\right]\left[\mathrm{Co}\left(\eta^{4}-\mathrm{PAC}\right)\right](0.08 \mathrm{mmol}, 4 \mathrm{~mm})$, iodosylbenzene, iodosylmesitylene, or pentafluorophenyliodosylbenzene $(0.52-0.54 \mathrm{mmol})$, and styrene $(7 \mathrm{mmol}, 350 \mathrm{mmol})$. The reaction was followed by gas chromatography (Carbowax $20 \mathrm{M}, 6 \mathrm{ft}$, stainless steel, $135^{\circ} \mathrm{C}$ ); styrene oxide, a small amount of phenylacetaldehyde, and iodobenzene (or iodomesitylene or pentafluoroiodobenzene) were detected (see Table 1). ${ }^{5}$ Oxidation products from the reaction using (1) and iodosylbenzene were separated by column chromatography on silica gel; iodobenzene and styrene were eluted with pentane, and styrene oxide and phenylacetaldehyde were eluted in that order with pentane-diethyl ether $(9: 1)$. The ${ }^{1} \mathrm{H}$ n.m.r. spectra of the separated products showed that the sytrene oxide to phenylacetaldehyde ratio was $4.75: 1$, a value close to that reported in the literature. ${ }^{6}$ The ratio obtained by g.c. was $c a$. 3.80 which suggests that some rearrangement from styene oxide to phenylacetaldehyde took place in the injector port ${ }^{6}\left(170^{\circ} \mathrm{C}\right)$ as was verified by control experiments. At the end of each catalytic oxidation the concentration of the square planar cobalt(III) complex was assessed and varying degrees of

Table 1. Results of catalytic oxidation studies on styrene using $\mathrm{Co}^{\mathrm{III}}$ complex. ${ }^{\mathrm{a}}$

\begin{tabular}{|c|c|c|c|c|c|}
\hline Complex & Oxidant & $\begin{array}{l}\text { Yield of } \\
\text { styrene oxide } \\
\text { + phenylacet- } \\
\text { aldehydeb }^{\text {aldehyde }}\end{array}$ & $\begin{array}{c}\text { Turnover } \\
\text { number }\end{array}$ & $\begin{array}{c}\text { Co } \\
\text { complex } \\
\text { remaining }\end{array}$ & $\begin{array}{l}\text { Duration } \\
\mathrm{c} / \mathrm{h}\end{array}$ \\
\hline \multirow[t]{4}{*}{$\mathrm{Na}(\mathbf{1})$} & PhIO & 56 & 3.7 & 44 & 1 \\
\hline & $\mathrm{PhIO}^{\mathrm{d}}$ & 41 & 2.8 & $\mathrm{e}$ & 2 \\
\hline & $\mathrm{C}_{6} \mathrm{~F}_{5} \mathrm{IO}$ & 26 & 2.0 & 0 & 1 \\
\hline & 6- $\mathrm{Me}_{3} \mathrm{C}_{6} \mathrm{H}_{2} \mathrm{IO}$ & 46 & 3.2 & 47 & 24 \\
\hline $\left.\mathrm{PPh}_{4}\right)(1)$ & $\mathrm{PhIO}^{\mathrm{d}}$ & 37 & 2.7 & $\mathrm{e}$ & 22 \\
\hline $\mathrm{Na}(2)$ & PhIO & 43 & 2.8 & 0 & 23 \\
\hline $\mathrm{Na}(3)$ & PhIO & 67 & 5.5 & 80 & 22 \\
\hline $\mathrm{Na}(4)$ & PhIO & 25 & 1.7 & 51 & 45 \\
\hline $\mathrm{Na}(5)$ & PhIO & 14 & 1.0 & $\mathrm{f}$ & 23 \\
\hline
\end{tabular}

a Reactions were performed at $0^{\circ} \mathrm{C}$ under a nitrogen atmosphere unless otherwise stated. b Percentage yield based on oxygen donor. c Percentage determined by u.v.-visible spectrophotometry. ${ }^{d}$ Reaction performed at room temperature. ${ }^{\mathrm{e}}$ Not measured. ${ }^{\mathrm{f}}$ Not determined because of overlapping absorptions.

$\ddagger$ Caution: Iodosylarenes, especially $\mathrm{C}_{6} \mathrm{~F}_{5} \mathrm{IO}$, are potentially explosive. ${ }^{5}$

$\dagger$ Contribution No. 7354 . 
decomposition were found; $c a .80 \%$ of (3) remained at the end of a typical experiment. Where catalysis was observed, the turnover number was limited by the amount of added iodosylarene and not by the lifetime of the added cobalt(III) complex; addition of further iodosylarene at the end of the cycle resulted in further catalytic oxidation.

While these catalytic processes are slow, the systems are noteworthy because of the possible intermediates that are implied. Following the mechanism that is becoming accepted for cytochrome-P450-like oxygen atom transfer reactions, 1 the catalytic yields of styrene oxide present indirect evidence for the possible existence of intermediate cobalt(v)-oxo complexes, i.e., species derived by oxygen atom transfer from the iodosylarene to square planar cobalt(III) that are isoelectronic with five-co-ordinate iron(Iv) ferryl complexes. In the case of $\mathrm{Na}(3)$, which gives the best catalyst system, the polyanionic chelating ligand can be regarded as an innocent ligand with respect to formal oxidation state assignments. Attempts to characterize intermediate species are in progress. However, it is possible that some degradation product is the active catalyst in this system, as is generally the case with metal complex catalyzed oxidations, and it should be noted that iodosylbenzene has been found to effect alkene oxidation on addition of cobalt(II) nitrate or trifluoromethanesulphonate. ${ }^{7}$ The presence of vacant sites on the metal centre of the added square planar complex appears to be important; addition of $\mathrm{Na}(5)\left(\mathrm{L}=\mathrm{H}_{2} \mathrm{O}\right)$ does not give an effective catalyst system. Alkene oxidation by cumyl hydroperoxide occurs catalytically in the presence of chloro(tetraphenylporphyrinato)cobalt(III); a radical mechanism was postulated. ${ }^{8}$ It has been suggested that, in the reaction of this complex with peroxycarboxylic acids, initial transfer of an oxygen atom to cobalt(III) yields a cobalt(v) species which, by rapid internal electron transfer, results in a porphyrin dication species of cobalt(III). ${ }^{9}$

We thank the Rohm and Haas Co., the Atlantic Richfield Corporation of America, and the National Science Foundation (Grant CHE-84-06198) for support of this work. S.O. thanks the Japanese Government for support for sabbatical leave from the University of Osaka. T.J.C. is a Dreyfus
Teacher-Scholar (1986-1990) and an Alfred P. Sloan Research Fellow (1986-1988).

Received, 13th January 1987; Com. 040

\section{References}

1 J. T. Groves, Ann. N.Y. Acad. Sci., 1986, 471, 99 (Int. Symp. Bioorg. Chem., 1985); J. P. Collman, T. Kodadek, and J. I. Brauman, J. Am. Chem. Soc., 1986, 108, 2588; B. R. Cook, T. J. Reinert, and K. S. Suslick, ibid., 1986, 108, 7281; I. Tabushi, M. Kodera, and M. Yokoyama, ibid., 1985, 107, 4466; T. G. Traylor, T. Nakano, B. E. Dunlap, P. S. Traylor, and D. Dolphin, ibid., 1986, 108, 2782; T. C. Bruice, Ann. N.Y. Acad. Sci., 1986, 471, 83 (Int. Symp. Bioorg. Chem., 1985); P. Battioni, J. P. Renaud, J. F. Bartoli, and D. Mansuy, J. Chem. Soc., Chem. Commun., 1986, 341; A. L. Balch, W. C. Yee, R. J. Cheng, G. N. La Mar, and L.-G. Lechoslaw, J. Am. Chem. Soc., 1984, 106, 7779; O. Bartolini and B. Meunier, J. Chem. Soc., Chem. Commun., 1983, 1364; C. K. Chang and M.-S. Kuo, J. Am. Chem. Soc., 1979, 101, 3413; J. R. Lindsay Smith and P. R. Sleath, J. Chem. Soc., Perkin Trans. 2, 1982, 1009.

2 J. C. Dobson, W. K. Seok, and T. J. Meyer, Inorg. Chem., 1986, 25, 1513; C. L. Hill and R. B. Brown, Jr., J. Am. Chem. Soc., 1986, 108, 536; E. G. Samel, K. Srinivasan, and J. Kochi, ibid., 1985, 107, 7606; C. M. Che and W. C. Chung, J. Chem. Soc., Chem. Commun., 1986, 229.

3 T. J. Collins, R. J. Coots, T. T. Furutani, J. T. Keech, G. T. Peake, and B. D. Santarsiero, J. Am. Chem. Soc., 1986, 108, 5333; F. C. Anson, T. J. Collins, S. L. Gipson, J. T. Keech, T. E. Krafft, and G. T. Peake, ibid., 1986, 108, 6593; F. C. Anson, T. J. Collins, S. L. Gipson, J. T. Keech, T. E. Kraft, B. D. Santarsiero, and G. H. Spies, ibid., 1984, 106, 4460; J. A. Christie, T. J. Collins, T. E. Krafft, B. D. Santarsiero, and G. H. Spies, J. Chem. Soc., Chem. Commun., 1984, 198.

4 T. J. Collins, T. G. Richmond, B. D. Santarsiero, and B. G. R. T. Treco, J. Am. Chem. Soc., 1986, 108, 2088.

5 J. P. Collman, Chem. Eng. News, 1985, 63, 2.

6 J. T. Groves and R. S. Myers, J. Am. Chem. Soc., 1983, 107, 5791.

7 R. B. VanAtta, C. C. Franklin, and J. S. Valentine, Inorg. Chem., 1984, 23, 4121.

8 D. Mansuy, J.-F. Bartoli, and M. Momenteau, Tetrahedron Lett., 1982, 23, 2781.

9 W. A. Lee and T. C. Bruice, Inorg. Chem., 1986, 25, 131. 